\title{
Growth impairment after TBI of leukemia survivors children: a model- based investigation
}

\author{
Chiara Galletto ${ }^{1 *}$, Antonio Gliozzi ${ }^{2}$, Daniele Nucera ${ }^{3}$, Nicoletta Bertorello ${ }^{1}$, Eleonora Biasin ${ }^{1}$, Andrea Corrias ${ }^{1}$, \\ Patrizia Chiabotto ${ }^{1}$, Franca Fagioli ${ }^{1}$ and Caterina Guiot ${ }^{4}$
}

\author{
* Correspondence: \\ chiara_galletto@libero.it \\ ${ }^{1}$ Pediatric Onco-Hematology, Stem \\ Cell Transplantation and Cellular \\ Therapy Division, Regina Margherita \\ Children's Hospital, piazza Polonia \\ 94, 10126 Turin, Italy \\ Full list of author information is \\ available at the end of the article
}

\begin{abstract}
Background: Children receiving Total Body Irradiation (TBI) in preparation for Hematopoietic Stem Cell Transplantation (HSCT) are at risk for Growth Hormone Deficiency (GHD), which sometimes severely compromises their Final Height (FH). To better represent the impact of such therapies on growth we apply a mathematical model, which accounts both for the gompertzian-like growth trend and the hormone-related 'spurts', and evaluate how the parameter values estimated on the children undergoing TBI differ from those of the matched normal population.

Methods: 25 patients long-term childhood lymphoblastic and myeloid acute leukaemia survivors followed at Pediatric Onco-Hematology, Stem Cell Transplantation and Cellular Therapy Division, Regina Margherita Children's Hospital (Turin, Italy) were retrospectively analysed for assessing the influence of TBI on their longitudinal growth and for validating a new method to estimate the GH therapy effects. Six were treated with GH therapy after a GHD diagnosis.
\end{abstract}

Results: We show that when TBI was performed before puberty overall growth and pubertal duration were significantly impaired, but such growth limitations were completely reverted in the small sample (6 over 25 ) of children who underwent GH replacement therapies.

Conclusion: Since in principle the model could account for any additional growth 'spurt' induced by therapy, it may become a useful 'simulation' tool for paediatricians for comparing the predicted therapy effectiveness depending on its timing and dosage.

Keywords: TBI, HSCT, GHD, Growth, Cancer survivors, Mathematical model

\section{Biomed Central}

\section{Background}

Growth is a finely regulated phenomenon that results from interaction of genetics, nutrition, hormones, metabolism and cerebrocortical influences: in childhood it is largely influenced by growth hormone $(\mathrm{GH})$ and in puberty by the synergistic action of GH and sex steroids. Puberty is the period of human development during which physical growth completes and sexual maturation occurs; this condition implies becoming first capable of sexual reproduction and is marked by the maturation of the genital organs and the development of the sexual secondary characteristics. The normal pubertal growth rate (complete enlargement degree) is approximately 1.5-2 times greater than the prepubertal growth rate. GH stimulates growth of epiphyseal cartilage and subsequent bone growth directly by action of Insulin-like growth factor

(c) 2014 Galletto et al.; licensee BioMed Central Ltd. This is an Open Access article distributed under the terms of the Creative Commons Attribution License (http://creativecommons.org/licenses/by/4.0), which permits unrestricted use, distribution, and reproduction in any medium, provided the original work is properly credited. The Creative Commons Public Domain Dedication waiver (http://creativecommons.org/publicdomain/zero/1.0/) applies to the data made available in this article, unless otherwise stated. 
I (IGF-1). When insufficient GH is produced, growth velocity and bone maturation are delayed and the divergence of the growth rate from normal increases with age unless replacement therapy is administered [1].

High-dose chemotherapy or chemo-radiotherapy followed by hematopoietic stem cell transplantation (HSCT) used to treat children with cancer has resulted in an ever-increasing number of long-term survivors. These patients are at risk for a variety of late effects due to the disease itself, treatment exposure (surgery, chemotherapy and radiotherapy) and possible underlying medical problems. Patients who received total body irradiation (TBI) in preparation for HSCT are at risk of developing a deficiency of one or more hormones produced by the hypothalamus and pituitary gland (HP region): both these treatments are known to affect growth and development. Chemotherapy, decreased nutritional intake, hematopoietic stem cell transplantation, corticosteroids and other endocrinological complications (hypothyroidism and hypogonadism) may also affect growth in childhood cancer survivors, but to a lower extent [2-4].

The incidence of GH deficiency (GHD) after TBI and HSCT varies from 20 to $85 \%$ depending upon differences in time of testing after HSCT, differences in preparative regimen received, inclusion of patients with and without cranial irradiation and use of different methods of GH testing, as described in a recent review [1].

It has been suggested that risk factors like higher CRT (cranial radiotherapy) dose, larger fraction size or larger number of fractions, increased volume of the HP region exposed, higher biological effective dose (BED), younger age at treatment and longer follow up time affect the risk of GHD secondary to radiation of the HP region [5,6]. In addition, gender (male sex) may also influence the prevalence of GHD. GH therapy is able to gain a total height inversely related to patient age at the start of GH treatment and positively related to its duration. Treatment with GH before the child's height has decreased to below the third percentile results in the greatest final height response to treatment. Growth before puberty is the major determinant of final height, therefore treatment with GH during the prepubertal period needs to be optimized.

Traditionally juvenile growth is evaluated by comparison with appropriate Height Growth Charts (HGC), which report proper statistical parameters (usually the $25^{\text {th }}$, $50^{\text {th }}$ and $75^{\text {th }}$ centiles of the heights extracted from measurements performed in large homogeneous populations) versus age (see for instance [7-9]). In order to model the growth from early childhood to maturity, alternative approaches have been proposed [10]. Gliozzi A et al. [11] have recently presented an alternative method for the fitting and modelling of human HGC and individual (longitudinal) growth curves, based on the formalism of the Phenomenological Universalities (PUN) [12], already used in the analysis of several datasets of great relevance for growth and to verify the influence of the different parameters.

We evaluated if such a model can be useful to assess the influence of TBI on longitudinal growth. In fact, given the differences between individual timing and sequence of the pubertal events, as well as the individual response to therapies, to compare the genuine patient growth data with proper 'growth chart' references can be misleading. On the contrary, the model uses the data of the patients for fitting the values of a few meaningful model parameters. Some of those parameters are related to the prepubertal growth, which in most cases are not influenced by TBI and other HSCT conditioning therapies, but simply reflect the individual 'growth potential'. Other parameters strictly 
describe pubertal growth, and are expected to be highly sensitive to TBI. Such values will be finally compared with those pertaining to the reference growth curve, aiming at assessing the quantitative impact of TBI on growth. The goal of the present paper is to validate this alternative method in a setting of long term leukemia survivors who underwent to HSCT and to assess if it would be able to estimate the GH therapy effects and to suggest a predictive algorithm to personalize GH therapy and to simulate its effect on the final height (FH).

\section{Methods}

\section{Patients and intervention}

Patients described in this monocentric retrospective study were all included in a long-term oncological and endocrinological follow-up or childhood lymphoblastic and myeloid acute leukaemia survivors performed at Pediatric Onco-Hematology, Stem Cell Transplantation and Cellular Therapy Division, Regina Margherita Children's Hospital, Turin, Italy; these children were diagnosed at Our Centre between 15/05/1988 and 29/06/2005. Although, according to the Italian regulations, for retrospective studies that did not involve additional withdrawals but only the extrapolation of data from existing medical records and where retrospective data is anonymous authorizations are not strictly due, we required and obtained the Ethic Committee approval (see Additional file 1).

Patients were eligible for this study if they met all the following inclusion criteria: (1) having undergone HSCT for childhood acute leukaemia after a myeloablative conditioning regimen, (2) having an italian origin, (3) having undergone an oncological and endocrinological at least 5-year long follow-up after HSCT with a complete growth evaluation (4) having at least one height measurement before TBI and a follow up lasting until sexual maturation. Patients who developed a second malignant tumor or who achieved final height in a short follow up period were excluded. Hormone therapy was never administered to promote puberty.

Out of 90 patients diagnosed and treated at our hospital between 1988 and 2005, twentyseven young long term survivors met these inclusion criteria and are described here. All patients has been followed by oncologists and endocrinologists possibly until the age of 18 and they all were in remission without complications at the time of this study. All the patients have been treated at our hospital according to the AIEOP (Associazione Italiana Ematologia-Oncologia Pediatrica-Italian Association of Pediatric Onco-Hematology)-BFM (Berlin-Frankfurt-Munster) ALL and AML Protocols, and had received TBI as part of their conditioning regimen before HSCT. Patients features are summarized in Table 1. Further details about patients who underwent GHT are given as Additional file 1.

Two female patients, one not (n. 19) and one (n. 26) undergoing GHT, were excluded by the samples because the estimated values were not reliable. In the first case the number of available data was too small to get a reasonable fitting of the parameters, in the second case we realized that GHT, delivered between 8 and 9 years of age, was very effective and the corresponding growth spurt was misinterpreted by the numerical program as the age of puberty.

\section{Preparative regimens to HSCT}

The preparative regimen depended on the protocols in use at the time of transplantation, the underlying disease and its status, and the existence or not of previous 
Table 1 Detailed list of the patients considered in the present study

\begin{tabular}{|c|c|c|c|}
\hline Patient & Sex & Age at TBI (years) & GH therapy $(\mathrm{Y} / \mathrm{N})$ \\
\hline 1 & $\mathrm{~F}$ & 8.4 & $\mathrm{~N}$ \\
\hline 2 & $\mathrm{~F}$ & 1.1 & N \\
\hline 3 & M & 10.4 & N \\
\hline 4 & M & 5.0 & N \\
\hline 5 & M & 6.3 & N \\
\hline 6 & $\mathrm{~F}$ & 6.9 & N \\
\hline 7 & $\mathrm{~F}$ & 7.0 & N \\
\hline 8 & M & 7.3 & N \\
\hline 9 & $\mathrm{~F}$ & 13.5 & N \\
\hline 10 & M & 10.6 & N \\
\hline 11 & M & 6.9 & Y \\
\hline 12 & $\mathrm{~F}$ & 11.2 & N \\
\hline 13 & $\mathrm{~F}$ & 4.9 & Y \\
\hline 14 & M & 14.2 & N \\
\hline 15 & $\mathrm{~F}$ & 12.7 & $N$ \\
\hline 16 & $\mathrm{~F}$ & 6.8 & Y \\
\hline 17 & $F$ & 6.3 & Y \\
\hline 18 & M & 8.0 & N \\
\hline 20 & M & 4.9 & Y \\
\hline 21 & M & 5.3 & N \\
\hline 22 & $\mathrm{~F}$ & 2.8 & N \\
\hline 23 & M & 12.2 & N \\
\hline 24 & $\mathrm{~F}$ & 7.3 & N \\
\hline 25 & $M$ & 13.0 & N \\
\hline 27 & $\mathrm{~F}$ & 9.3 & $Y$ \\
\hline
\end{tabular}

central nervous system (CNS) irradiation. TBI was always administered fractionated and all patients received the same total dose of 12 Gy (that is, 2Gy twice daily during 3 days). TBI was associated to etoposide, to etoposide and cyclophosphamide, to melphalan (5 patients respectively), to thiotepa and cyclophosphamide (5 patients), to cyclophosphamide and to fludarabine (1 patient in both cases), to fludarabine and thiotepa (2 patients).

\section{Growth evaluation}

Height was measured at first diagnosis, at the beginning of the second line therapy in case of leukemia relapse, at starting of preparative regimen to HSCT and then every six/twelve months until 18 years of age, as part of endocrinological examinations follow up. From these measurements it was possible to obtain information on the pubertal growth in terms of overall growth (complete enlargement) and growth velocity (heightening speed; $\mathrm{cm}$ /year). Standing height, measured using a Harpenden stadiometer, was used for all patients. Final height (FH) was defined as the tallest height measured when the patient's age was 18 years or older, and when height velocity was less then $1 \mathrm{~cm}$ per year. 


\section{Growth hormone deficiency (GHD)}

The diagnosis of GHD in childhood is a multifaceted process requiring comprehensive clinical and endocrinological assessment, combined with biochemical tests of the $\mathrm{GH}$-insulin-like-growth factor (IGF) axis. Criteria to initiate investigation include: 1) severe short stature, defined as a height more than 3SD below the mean; 2) height more than 1.5 SD below the midparental height; 3) height more than 2SD below the mean and a height velocity over 1 yr more than 1 SD below the mean for chronological age, or a decrease in height SD more than 0.5 over 1 yr in children over 2 yr of age; 4) in the absence of short stature, a height velocity more than 2 SD below the mean over 1 yr or more than 1.5 SD sustained over $2 \mathrm{yr}$.

Growth hormone $(\mathrm{GH})$ deficiency was detected by measuring insulin-like growth factor I plasma levels and $\mathrm{GH}$ peak response to at least two stimulation tests per patient (first test: Arginine, second test glucagon or insulin). GH insufficiency was diagnosed when peak GH levels after stimulation were inferior to $10 \mathrm{mcg} / \mathrm{L} \mathrm{[13].}$

For patients who underwent a GH therapy we considered: length at birth, target height; somatomedins and other biochemical abnormalities at the start of therapy; age at beginning of GH therapy dose and duration. Nobody had thyroid disfunction; only one patient had gonadal disfunction (patient 6) (see Additional file 1).

\section{Physical model}

Growth is described, according to [11] and the parameters listed in Table 2, using an algorithm which assumes that, starting from an initial height $y_{0}$, (actually corresponding to 3-months stature) a gompertzian [14] lengthening with growth rate $\mathrm{a}_{0}$ and carrying capacity related parameter $\mathrm{k}_{0}$ occurs.

Following endogenous hormones production, growth shows accelerations or 'spurts' at mid-childhood and at adolescence. The last, concomitant with puberty, is the predominant one and can be modeled as a Gaussian-like velocity spurt with growth rate $\mathrm{a}_{1}$ occurring at the average age of $t_{m}$, and with a time distribution given by a variance $\sigma$, which causes an overgrowth $\mathrm{y}_{1}$.

The above model can be expressed by the Eq:

$$
y=y_{0} \exp \left(\frac{k_{0}}{a_{0}}\left(1-\exp \left(-a_{0} t\right)\right)\right)+y_{1} \exp \left(\frac{k_{0}}{a_{1}}\left(1-\exp \left(-a_{1}\left(t-t_{m}\right)\right)\right) G\left(t_{m}, \sigma\right)\right)
$$

being $\mathrm{G}$ the Gauss cumulative function:

$$
G\left(t_{m}, \sigma\right)=\frac{1}{\sqrt{2 \pi}} \int_{-\infty}^{\infty} e^{\frac{\left(t-t_{m}\right)^{2}}{2 \sigma_{m}{ }^{2}}} d t
$$

The above equations can be used for fitting individual growth data (longitudinal studies) as well as HGC (transversal studies) [7-9]. A dedicated MATLAB ${ }^{\oplus}$ program fitted the parameter values which best interpolate the growth curve of the model with the available data describing the height of each patient. A more exhaustive explanation of the mathematical procedure can be found in Gliozzi et al. [11]. 
Table 2 Detailed list of parameter values evaluated by the model

\begin{tabular}{|c|c|c|c|c|c|c|c|c|}
\hline & Case & $\begin{array}{l}Y_{0} \\
\text { (height at } \\
3 \text { months } \\
\text { in } \mathrm{cm} \text { ) }\end{array}$ & $\begin{array}{l}\mathbf{k}_{0} \\
\text { (carrying } \\
\text { capacity) }\end{array}$ & $\begin{array}{l}a_{0} \text { (pre- } \\
\text { pubertal } \\
\text { growth } \\
\text { rate) }\end{array}$ & $\begin{array}{l}t_{m} \\
\text { (age at } \\
\text { puberty) }\end{array}$ & $\begin{array}{l}\mathrm{y}_{1} \\
\text { (overgrowth } \\
\text { due to puberty } \\
\text { in } \mathrm{cm} \text { ) }\end{array}$ & $\begin{array}{l}a_{1} \\
\text { (pubertal } \\
\text { growth } \\
\text { rate) }\end{array}$ & $\begin{array}{l}\sigma \text { (puberty } \\
\text { time span } \\
\text { in yrs) }\end{array}$ \\
\hline & 1 & 62.39727 & 0.190254 & 0.218913 & 11.84713 & 12.22394 & 4.497026 & 0.591718 \\
\hline \multirow[t]{14}{*}{ Females } & 2 & 56.18536 & 0.26937 & 0.276819 & 10.50654 & 8.135071 & 1.232418 & 1.748695 \\
\hline & 6 & 58.33898 & 0.248981 & 0.294922 & 11.18104 & 11.66339 & 1.030791 & 1.519584 \\
\hline & 7 & 63.2854 & 0.1975 & 0.2324 & 9.655209 & 7.9907 & 7.2763 & 0.3051 \\
\hline & 9 & 62.229 & 0.192012 & 0.217 & 10.25788 & 9.588047 & 1.399609 & 1.212012 \\
\hline & 12 & 62.33923 & 0.192248 & 0.224598 & 13.43577 & 6.946294 & 6.07616 & 1.31218 \\
\hline & 15 & 63.92922 & 0.172435 & 0.198459 & 10.84313 & 5.841731 & 9.715973 & 0.577892 \\
\hline & 22 & 62.3936 & 0.1903 & 0.2189 & 10.85878 & 12.2237 & 4.4767 & 0.5918 \\
\hline & 24 & 53.83767 & 0.257778 & 0.274054 & 12.86398 & 9.008473 & 7.301078 & 1.27438 \\
\hline & 13 & 70.89 & 0.097948 & 0.110792 & 10.16677 & 5.630503 & 4.339571 & 0.667967 \\
\hline & 16 & 73.39873 & 0.08876 & 0.119807 & 12.92137 & 18.89658 & 5.471942 & 0.17205 \\
\hline & 17 & 61.28031 & 0.19219 & 0.271627 & 11.60383 & 28.09531 & 0.869462 & 4.42738 \\
\hline & 27 & 60.32773 & 0.201376 & 0.217701 & 11.45546 & 2.54826 & 1.79574 & 0.001265 \\
\hline & $\begin{array}{l}\text { Reference } \\
\text { values } 50 \text { th } \\
\text { centile HGC }\end{array}$ & 61.94 & 0.187 & 0.218 & 10.31 & 15.24 & 0.61 & 2.01 \\
\hline & 3 & 72.35844 & 0.101311 & 0.135207 & 13.7949 & 7.091698 & 1.333014 & 0.670117 \\
\hline \multirow[t]{12}{*}{ Males } & 4 & 68.32549 & 0.146165 & 0.189528 & 20.01918 & 3.759593 & 4.040935 & 3.719143 \\
\hline & 5 & 66.97872 & 0.146127 & 0.161664 & 12.5558 & 6.622826 & 2.100794 & 0.592351 \\
\hline & 8 & 71.88692 & 0.10269 & 0.122161 & 12.89852 & 8.895164 & 4.251733 & 1.715174 \\
\hline & 10 & 65.03691 & 0.164741 & 0.169928 & 11.92245 & 6.199538 & 9.831924 & 0.705535 \\
\hline & 14 & 61.74667 & 0.212759 & 0.244471 & 11.54411 & 15.17584 & 0.679802 & 2.016547 \\
\hline & 18 & 67.1999 & 0.129419 & 0.14843 & 13.2384 & 11.72742 & 2.069234 & 0.817563 \\
\hline & 21 & 78.24132 & 0.065035 & 0.090613 & 14.88816 & 17.0507 & 1.35473 & 0.851504 \\
\hline & 23 & 69.22207 & 0.137272 & 0.154906 & 15.0422 & 6.979829 & 2.339744 & 0.525147 \\
\hline & 25 & 69.0407 & 0.138559 & 0.148518 & 12.96021 & 13.12342 & -0.18501 & 1.492829 \\
\hline & 11 & 66.39639 & 0.148124 & 0.204369 & 12.50947 & 11.13404 & 1.148798 & 1.087921 \\
\hline & 20 & 75.0882 & 0.099678 & 0.123619 & 11.29312 & 6.9798 & 2.3397 & 0.5251 \\
\hline & $\begin{array}{l}\text { Reference } \\
\text { values } 50 \text { th } \\
\text { centile HGC }\end{array}$ & 67.82 & 0.136 & 0.149 & 12.79 & 14.73 & 0.84 & 1.45 \\
\hline
\end{tabular}

Patients reported in bold underwent $\mathrm{TBI}+\mathrm{GH}$ therapy.

\section{Statistical analysis}

The difference $\Delta$ between the values estimated by the model for each patient given in Table 2 and the $50^{\text {th }}$ centile of appropriate HGC has been computed for each variable. The sample size is given in brackets. The mean and the related 95\% Confidence Interval (95\% C.I.) of $\Delta$ were calculated for all the patient of the study $(\mathrm{N}=25)$, for those undergoing TBI but not GH therapy $(\mathrm{N}=19)$ and for male $(\mathrm{N}=10)$ and female $(\mathrm{N}=9)$ separately. Similar statistics were calculated for the group of children who received both TBI and GH therapy $(\mathrm{N}=6)$. In this analysis gender was not considered for the limited sample size available. Whenever the range of $\Delta$ corresponding to the $95 \%$ C.I. did not overlap the vertical line of null values, the result was considered significantly $(\mathrm{p}=0.05)$ different from the null hypothesis. The central point of the $\Delta$ range is the mean value of the difference 
between the parameter value evaluated in the sample and in the reference population: being it negative (positive) means that the parameter is smaller (larger) of the given extent than expected.

\section{Results}

Figure 1 ( $\mathrm{a}$ and $\mathrm{b}$ ) reports the height of the 12 males and 13 females included in the present study, comparing their stature with their reference, i.e. the 50-th centile of appropriate HGC. The 25-th centile is reported as well. It shows that growth is severely impaired and the Final Height is always lower than the reference values except for one case (male n.25).

As shown in Figure 2, assuming as reference the $50^{\text {th }}$ centiles of appropriate HGC, we considered the patients undergoing TBI without a following GH therapy $(\mathrm{n}=19)(\mathrm{b})$ 10 males and 9 females undergoing TBI (c) and we compared them to their reference. The statistical analysis showed that the 19 patients undergoing TBI exhibited a normal pre-pubertal growth but significantly differ from their reference in the overall pubertal growth $(-5.5 \mathrm{~cm})$, in the pubertal growth velocity $(+3.0 \mathrm{~cm} / \mathrm{yr})$ and in the average $(+1.0 \mathrm{yr})$ and standard deviation of the time of pubertal growth $(-0.5 \mathrm{yr})$. Moreover, when the genders were separately considered, all the above parameters were still significantly different from normal for females, while the males who underwent TBI only show a reduced pubertal growth in comparison with their reference.

Comparing patients undergoing TBI before $(\mathrm{n}=14)$ (Figure 3a) and after the average time of puberty $(n=5)$ (Figure $3 b)$ versus the respective reference, we observed that patients undergoing TBI before puberty $(\mathrm{n}=14)$ showed a delayed mean pubertal age $(+1.34 \mathrm{yr})$, a reduced pubertal growth $(-5.9 \mathrm{~cm})$, an increased post-pubertal growth
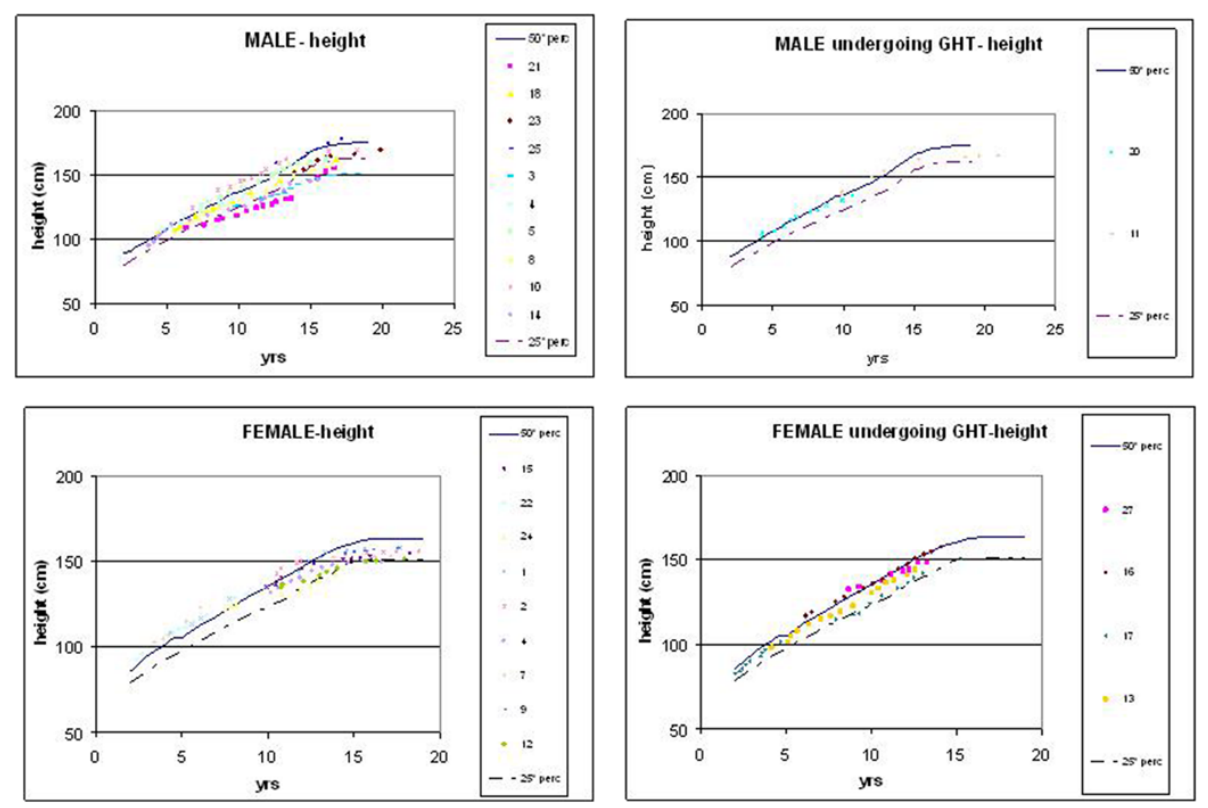

Figure 1 Reports the height of the 12 males and 13 females considered in the present study, comparing their stature with the 50-th and 25-th centile of appropriate HGC. Patients are divided between those who have not (on the left) and those who have (on the right) undergone Growth Hormone Therapy (GHT). 


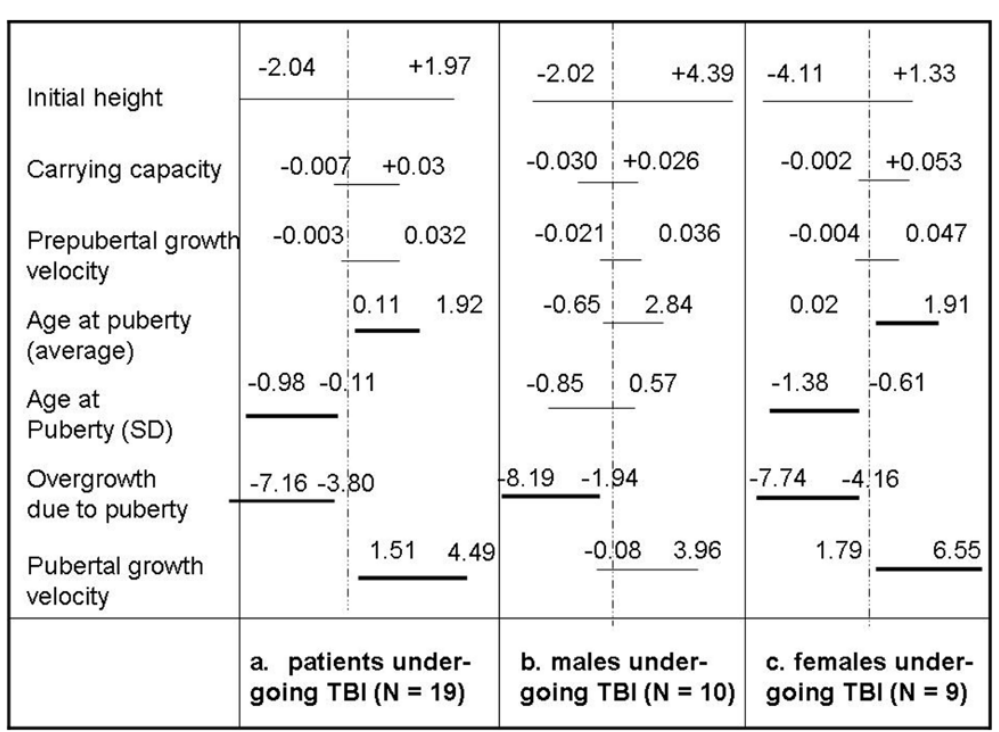

Figure 2 Plot of the $95 \%$ Confidence Interval of the variable $\Delta=$ value estimated by the model on the sample - value estimated by the model on the $50^{\text {th }}$ centile of appropriate HGC for all the model parameters. The considered samples are the total of the patients undergoing TBI but not GH therapy (a), the subsample formed by the males (b) and by the females (c).

velocity $(+3.2 \mathrm{~cm} / \mathrm{yr})$ and a shorter value of the standard deviation of the pubertal time $(-0.6 \mathrm{yr})$. Those undergoing TBI later than puberty showed a normal growth.

Six patients (4 females and 2 males) received GH therapy after TBI and HSCT. As described in Figure 4, if we add to the previous sample $(\mathrm{N}=19)$ also these patients, the same parameters which significantly differed from normal population still did so. Due

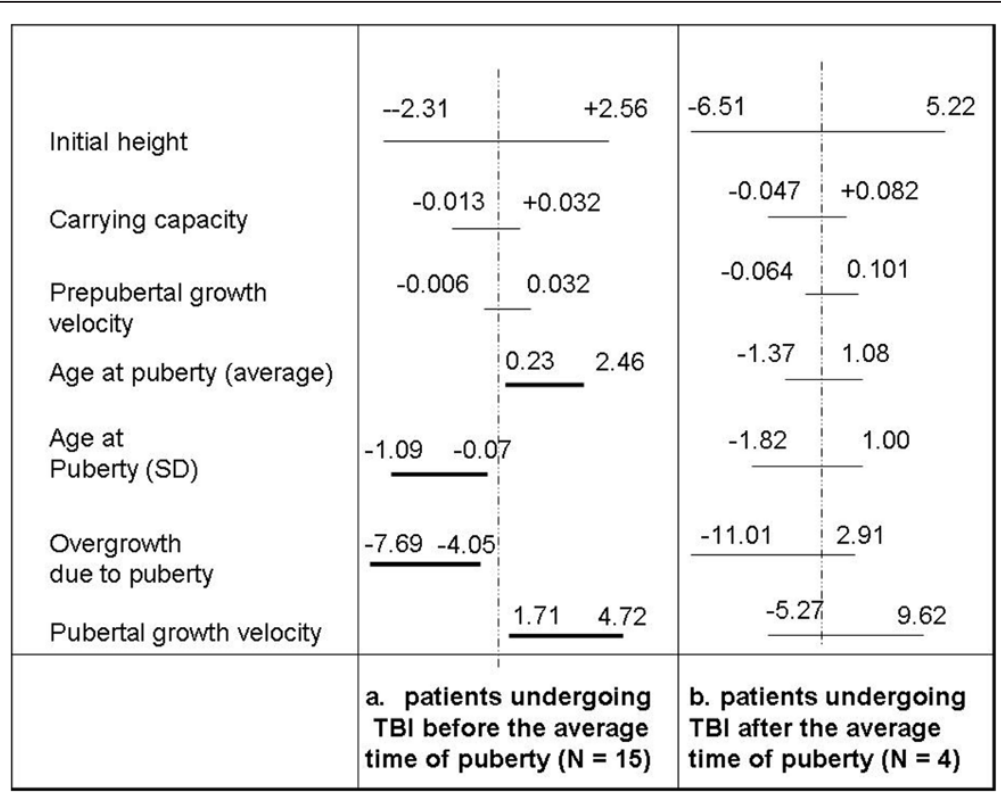

Figure 3 Plot of the $95 \%$ Confidence Interval of the variable $\Delta=$ value estimated by the model on the sample - value estimated by the model on the $50^{\text {th }}$ centile of appropriate HGC for all the model parameters. The considered samples are the patients undergoing TBI before (a) and after (b) the average time of puberty. 


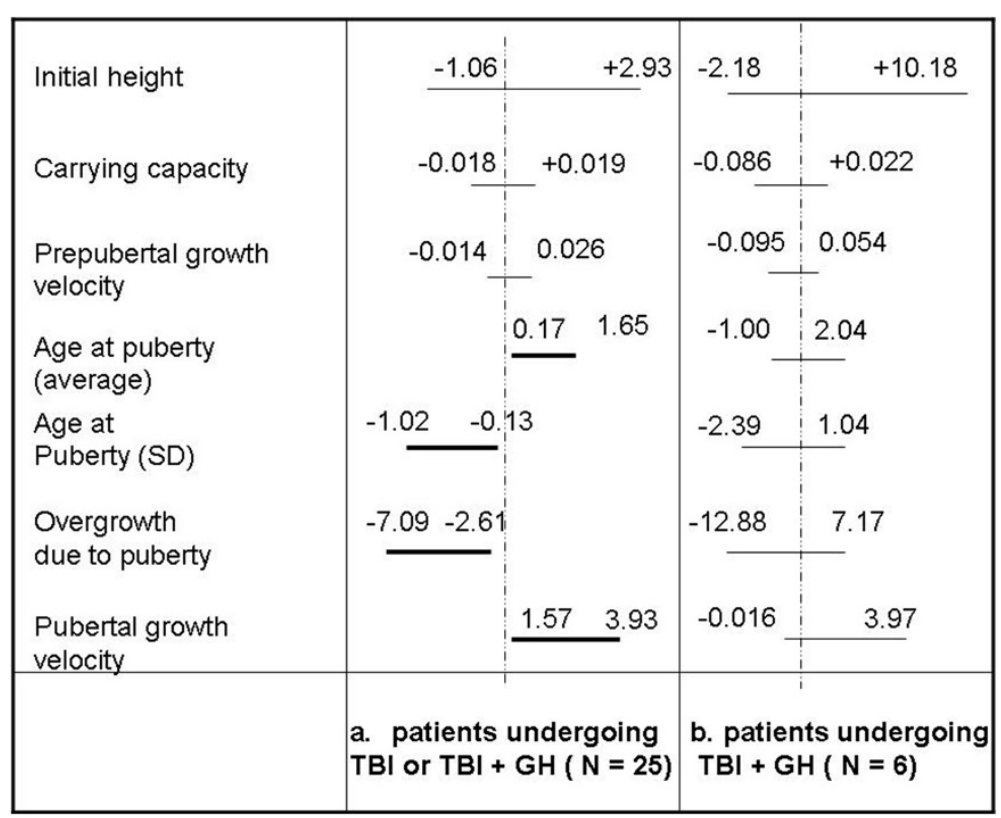

Figure 4 Plot of the $95 \%$ Confidence Interval of the variable $\Delta=$ value estimated by the model on the sample - value estimated by the model on the $50^{\text {th }}$ centile of appropriate HGC for all the model parameters. The considered samples are the patients undergoing only $\mathrm{TBI}$ or $\mathrm{TBI}+\mathrm{GH}$ therapy (a) and those undergoing $\mathrm{TBI}+\mathrm{GH}$ therapy (b).

to the reduced proportion (6 over 25) it seems conceivable that the parameter values evaluated for this sample has a low 'weight' in comparison with those pertaining to the other 19 patients who didn't undergo any GH replacement therapy.

Finally, comparing growth after TBI $(\mathrm{N}=19)$ with TBI $+\mathrm{GH}$ therapy $(\mathrm{N}=6)$, the statistical analysis showed that no one of the above considered parameter significantly differed anymore from those pertaining to the normal population. GH therapy proved therefore effective in reversing the effect of TBI on pubertal growth. Such a 'catch up' effect is quite interesting and, although few $(\mathrm{N}=6)$ cases have been studied up to now, gives a very positive feedback about the effectiveness of the GH replacement therapy administered in our clinical context.

\section{Discussion and conclusions}

Intensive chemotherapy regimens with or without CNS irradiation are associated with persistent growth impairment [1,2,15-17], a multifactorial process implicating first-line treatments, post transplant complications and their consecutive treatments, prolonged use of steroid for GVHD and myeloablative conditioning regimens [18-22] either following TBI or cranial radiotherapy, which has similar effects on the hypothalamus and pituitary gland. Conditioning regimens seem to alter growth throughout the combined effects of lesions of the hypothalamic-pituitary gland axis, multiple endocrine dysfunction (thyroid and gonadal) and damage to the bone epiphyses [1,23-27].

In our study 25 long-term leukemia survivors were retrospectively analyzed for assessing the influence of TBI on their longitudinal growth and for validating a new method to estimate the GH therapy effects. Six were treated with GH therapy after a GHD diagnosis. 
The values of the parameters entering the model were estimated for all the patients and compared with the values corresponding to the $50^{\text {th }}$ centile of the appropriate HGC. All the values of the parameters referring to the prepubertal status $\left(y_{0}, a_{0}, k_{0}\right)$ were never significantly different from those of the normal population, confirming that TBI and all the related therapies were delivered to a sample extracted by the general population. On the contrary, TBI impacted on the post-puberal parameters both for males and females and also GH therapy following TBI and HSCT proved effective in compensating TBI-induced growth limitation. Our analysis confirms that TBI severely affects the post-pubertal growth parameters, mainly the overall growth and the pubertal duration, expecially when it was performed before puberty [28]. Although only a very small sample was available, we also showed that the above growth limitations are significantly reduced when GH therapy follows TBI. Furthermore, a possible bias of the program has to be assessed, since the program interprets any growth discontinuity, maybe due to effective GHT, as puberty. A careful check of the data should always been performed before processing.

In conclusion, the value of the post-pubertal parameters have been shown to be changed by GH therapy but, due to the small number of patients included in the present study, we were unable to relate those value to very important factors, such as the specific drug and dosage, the age at which the therapy was started, its duration, etc. At the moment we can just speculate that such mathematical approach can open a new working prospective towards 'personalized treatments'. A larger, possible multicentric, study could in principle discriminate all the above factors and evaluate their specific different impact on the model parameters. At that time, being the model able to produce longitudinal curves on the basis of the values of those parameters, it could be used as a sort of "clinical simulator" in order to predict the final effect of any specific dose of GH and, even more remarkably, of the timing of the therapeutic treatment, helping pediatricians and endocrinologists to find the best clinical protocol for follow up and treatment also in long term cancer survivors.

\section{Additional file}

Additional file 1: Details about the GHT.

Competing interest

The authors declare that they have no competing interests.

Authors' contributions

NB, EB, AC and FF participated to the acquisition, analysis and interpretation of data; AG and DN participated in the design of the study and performed the SW program for data elaboration and the statistical analysis, CG \& CG (first and last authors) conceived the study, participated in its design and coordination and drafted the manuscript. All authors read and approved the final manuscript.

Acknowledgements

The study was supported by the $60 \%$ grant of University of Torino.

Author details

'Pediatric Onco-Hematology, Stem Cell Transplantation and Cellular Therapy Division, Regina Margherita Children's Hospital, piazza Polonia 94, 10126 Turin, Italy. ${ }^{2}$ Department of Physics, Politechnics of Turin, Turin, Italy. ${ }^{3}$ Department of Animal Pathology, University of Turin, Turin, Italy. ${ }^{4}$ Department of Neuroscience, University of Turin, Turin, Italy. 
References

1. Sanders JE: Growth and development after hematopoietic cell transplant in children. Bone Marrow Transplant 2008, 41:223-227.

2. Brauner R, Adan L, Souberbielle JC, Esperou H, Michon J, Devergie A, Gluckman E, Zucker JM: Contribution of growth hormone deficiency to the growth failure that follows bone marrow transplantation. J Pediatr 1997, 130:785-792.

3. Huma Z, Boulad F, Black P, Heller G, Sklar CA: Growth in children after bone marrow transplantation for acute leukemia. Blood 1995, 86:819-824.

4. Shalet SM, Toogood A, Rahim A, Brennan BM: The diagnosis of growth hormone deficiency in children and adults (Review). Endocr Rev 1998, 19:203-223.

5. Mulder RL, Kremer LCM, van Santen HM, Ket JL, van Trotsenburg ASP, Koning CCE, Schouten-van Meeteren AYN, Caron HN, Neggers SJCMM, van Dalen EC: Prevalence and risk factors of radiation-induced growth hormone deficiency in childhood cancer survivors: a systematic review. Cancer Treat Rev 2009, 35:616-632.

6. Darzy KH, Shalet SM: Hypopituitarism following radiotherapy. Pituitary 2009, 12(1):40-50.

7. Tanner JM, Whitehouse RH, Takaishi M: Standards from birth to maturity for height, weight, height velocity, and weight velocity: British children, 1965 II. Arch Dis Child 1966, 41(220):613-635.

8. Tanner JM, Whitehouse RH: Clinical longitudinal standards for height, weight, height velocity, weight velocity and stages of puberty. Arch Dis Child Mar 1976, 51(3):170-179.

9. Tanner JM, Cameron N: Investigation of the mid-growth spurt in height, weight and limb circumferences in single-year velocity data from the London, 1966-67 growth survey. Ann Hum Biol 1980, 7(6):565-577.

10. Fujii K: Connection between Growth/Development and Mathematical Functions. Int I Sport Health Sci 2006 , 4:216-232.

11. Gliozzi AS, Guiot C, Delsanto PP, lordache DA: A novel approach to the analysis of human growth. TBMM 2012, 9:17. doi:10.1186/1742-4682-9-17.

12. Castorina P, Delsanto PP, Guiot C: Classification scheme for phenomenological Universalities in growth problems in physics and other sciences. Phys Rev Lett 2006, 96:188701.

13. Growth Hormone Research Society: Consensus guidelines for the diagnosis and treatment of Growth Hormone (GH) deficiency in childhood and adolescence: summary statement of the GH Research Society. J Clin Endocrinol Metab 2000, 85:3990-3993.

14. Gompertz B: On the nature of the function expressive of the law of human mortality and on a new mode of determining life contingencies. $R$ Soc London 1825, 123:513.

15. Robinson LL, Nesbit ME Jr, Sather HN, Meadows AT, Ortega JA, Hammond GD: Height of children successfully treated for acute lymphoblastic leukemia: a report from the late effects study committee of children's cancer study group. Med Pediatr Oncol 1985, 13:14-21.

16. Sanders JE, Buckner CD, Sullivan KM, Doney K, Appelbaum F, Witherspoon R, Storb R, Thomas ED: Growth and development in children after bone marrow transplantation. Horm Res 1988, 30:92-97.

17. Sanders JE, Pritchard S, Mahoney P, Amos D, Buckner CD, Witherspoon RP, Deeg HJ, Doney KC, Sullivan KM, Appelbaum FR: Growth and development following marrow transplantation for leukemia. Blood 1986, 68:1129-1135.

18. Bernard F, Bordigoni P, Simeoni M-C, Barlogis V, Contet A, Loundou A, Thuret I, Leheup B, Chambost H, Play B, Auquier P, Michel G: Height growth during adolescence and final height after haematopoietic SCT for childhood acute leukaemia: the impact of a conditioning regimen with BU or TBI. Bone Marrow Transplant 2009, 43:637-642.

19. Cicognani A, Cacciari E, Rosito P, Mancini AF, Carla G, Mandini M, Paolucci G: Longitudinal growth and final height in longterm survivors of childhood leukaemia. Eur J Pediatr 1994, 153(10):726-730.

20. Davies HA, Didcock E, Didi M, Ogilvy-Stuart A, Wales JK, Shalet SM: Growth, puberty and obesity after treatment for leukaemia. Acta Paediatr Suppl 1995, 411:45-50.

21. Chow EJ, Friedman DL, Yasui Y, Whitton JA, Stovall M, Robison LL, Sklar CA: Decreased adult height in survivors of childhood acute lymphoblastic leukemia: a report from the Childhood Cancer Survivor Study. J Pediatr 2007, 150:370-375.

22. Viana MB, Vilela Ml: Height deficit during and many years after treatment for acute lymphoblastic leukemia in children: a review. Pediatr Blood Cancer 2008, 50:509-516.

23. Fletcher BD, Crom DB, Krance RA, Kun LE: Radiation induced bone abnormalities after bone marrow transplantation for childhood leukemia. Radiology 1994, 191:231-235.

24. Michel G, Socié G, Gebhard F, Bernaudin F, Thuret I, Vannier JP, Demeocq F, Leverger G, Pico JL, Rubie H, Mechinaud F, Reiffers J, Gratecos N, Troussard X, Jouet JP, Simonin G, Gluckman E, Maraninchi D: Late effects of allogeneic bone marrow transplantation for children with acute myeloblastic leukemia in first complete remission: the impact of conditioning regimen without total-body irradiation-a report from the Societe Francaise de Greffe de Moelle. J Clin Oncol 1997, 15(6):2238-2246.

25. Socié G, Salooja N, Cohen A, Rovelli A, Carreras E, Locasciulli A, Korthof E, Weis J, Levy V, Tichelli A: Late effects working party of the European Study Group for blood and marrow transplantation. Non malignant late effects after allogeneic stem cell transplantation. Blood 2003, 101:3373-3385.

26. Sanders JE, Guthrie KA, Hoffmeister PA, Woolfrey AE, Carpenter PA, Appelbaum FR: Final adult height of patients who received hematopoietic cell transplantation in childhood. Blood 2005, 105:1348-1354.

27. Couto-Silva AC, Trivin C, Esperou H, Michon J, Baruchel A, Lemaire P, Brauner R: Final height and gonad function after total body irradiation during childhood. Bone Marrow Transplant 2006, 38:427-432.

28. Bakker B, Massa GG, Oostdijk W, Van Weel-Sipman MH, Vossen JMWit JM: Pubertal development and growth after total-body irradiation and bone marrow transplantation for haematological malignancies. Eur J Pediatr 2000, 159(1-2):31-7.

doi:10.1186/1742-4682-11-44

Cite this article as: Galletto et al: Growth impairment after TBI of leukemia survivors children: a model- based investigation. Theoretical Biology and Medical Modelling 2014 11:44. 